\title{
Masones en el interior argentino: su funcionamiento, sus redes de vinculación y su disidencia religiosa (1907-1924)
}

\section{Freemasons in the Argentinean interior: its functioning, its networks and its religious dissidence (1907-1924)}

Universidad Nacional de La Pampa, Argentina

Ana María T. Rodríguez

anmarodri@hotmail.com

Recepción: 15 de agosto de 2017/Aceptación: 22 de octubre de 2017

doi: https://doi.org/10.15517/rehmlac.v9i2.29481

Palabras clave

Argentina; Territorio Nacional de La Pampa; logias; masonería; disidencia religiosa.

Keywords

Argentina; National Territory of La Pampa; Lodges; Freemasonry; Religious Dissidence.

Resumen

En este artículo estudiamos las logias que surgieron en las primeras décadas del siglo XX en el interior argentina, concretamente en el Territorio Nacional de La Pampa, un espacio incorporado al Estado Nacional Argentino luego de la llamada Conquista al Desierto (1879). Centramos el análisis en la indagación sobre el origen y declinación de cuatro logias: Libertad (General Acha 1907-1910), Estrella de La Pampa (Santa Rosa1907-1912), Luz de La Pampa (General Pico, 1909-1914), Triángulo Luz de La Pampa (Catriló, 1923-1924), su funcionamiento y las redes de vinculación con otras asociaciones de la sociedad. Asimismo, interpretamos la relación que establecieron con la Iglesia católica en tanto fueron asociaciones que disputaron con el catolicismo sobre el rumbo que debía adquirir el territorio pampeano.

Abstract

In this article we study the lodges that emerged in the first decades of the 20th century in the provinces of Argentina, specifically in the National Territory of La Pampa, a space incorporated to the Argentine State after the "Conquest to the desert" (1879). We focus on the origin and decline of four lodges: Liberty (General Acha 1907-1910), Star of La Pampa (Santa Rosa-1907-1912), Luz de La Pampa (General Pico, 1909-1914), Triangle Light of La Pampa (Catriló, 1923-1924), its functions, its networks and their connections with other civil associations. We also consider the relationship that these lodges established with the Catholic Church as they disagreed with Catholicism over the course that the territory of La Pampa should acquire. 


\section{Introducción}

Tal como ha planteado Bandieri ${ }^{1}$ los territorios nacionales argentinos $\mathrm{y}$, de manera especial, aquellos que fueron asiento de las nuevas autoridades territoriales sin la tradición católica imperante en las más antiguas provincias argentinas, atrajeron especialmente a los cultores de las ideas del liberalismo laicista de la época, como es el caso de la masonería, garantizando su exitosa mediación entre la sociedad civil y el poder. En el caso del Territorio Nacional de La Pampa ${ }^{2}$ varias logias locales -Libertad (General Acha, 19071910), Estrella de La Pampa (Santa Rosa, 1907-1912), Luz de La Pampa (General Pico, 1909-1914), Triángulo Luz de La Pampa (Catriló, 1923-1924) ${ }^{3}$-iniciaron sus actividades desde principios de siglo XX hasta su declinación definitiva a mediados de la década de $1920^{4}$.

\footnotetext{
${ }^{1}$ Susana Bandieri, "Sociedad civil y redes de poder social en los territorios nacionales del sur: Neuquén, Patagonia argentina. 1880-1907”, Boletín Americanista LVII, no. 57 (2007): 53-68.

${ }^{2}$ La Pampa fue Territorio Nacional a partir de la Ley 1532 del año 1884. Por esta norma, se delimitaron y organizaron nueve entidades jurídicas: Misiones, Formosa, Chaco, La Pampa, Neuquén, Río Negro, Chubut, Santa Cruz y Tierra del Fuego. La Ley de Territorios Nacionales, entonces, dio origen a nuevas áreas en los márgenes de las provincias históricas, que habían estado bajo el dominio de diversas parcialidades indígenas. La Ley 1532 estableció la organización de los tres poderes de gobierno de estos territorios con sus respectivas obligaciones: el Poder Ejecutivo, personificado en la figura de un gobernador nombrado por el presidente de la Nación con acuerdo del Senado; el Poder Judicial, formado por los jueces letrados y los jueces de paz, éstos últimos elegidos por el ejecutivo local en las poblaciones con menos de 1.000 habitantes y por los territorianos en las localidades que superaban esos niveles; y el Poder Legislativo, conformado por los concejos municipales que se formaron sólo en localidades con más de 1.000 habitantes. Esta ley también fijó los deberes y atribuciones de los gobernadores. Estableció que debía proponer los empleados de la gobernación, recibir las asignaciones del presupuesto, controlar e informar las inversiones mensualmente, nombrar autoridades policiales y jueces de paz, crear reservaciones indígenas y velar por el progreso de la enseñanza. La vigencia de dicha norma se hizo extensiva por un lapso de 70 años. Marisa Moroni, María Esther Folco, María de los Ángeles Lanzillota, Mirta Zink y Martín Bergia, "Evolución política entre 18901950", en Historia de La Pampa. Sociedad, politica, economía. Desde los poblamientos iniciales hasta la provincialización (ca. 8000 AP a 1952), eds. A. Lluch y C. Salomón Tarquini (Santa Rosa: Miño y DávilaEdUNLPam, 2008), 321-344.

${ }^{3}$ Sólo estudiamos estas cuatro logias que son las que se dispone de material documental a pesar de que existen referencias sobre la existencia de otras. El II Álbum Biográfico de los Libre Pensadores de 1916, referencia a los principales librepensadores de la Argentina, cuyos integrantes en alta proporción eran miembros de logias masónicas. Como material documental ofrece un panorama general del alcance del movimiento en la Argentina y también referencia al Territorio. Adhieren hombres y mujeres. En Santa Rosa se encuentra a Ramón Pardo López, Aurora y Rosa Pardo; en Hucal a Guerino Manfredi, Isolina Manfredi; en Santa Teresa a Florentino Vázquez (Organización de la Augusta Liga 26 de Julio), Juan Rossi, Alcira Vasallo Rossi; en Chapaleufú a Alejo Elorza; en Colonia Barón a Dolores Lobos Suarez e hijos Araceli y Fernando; en General Pico a Victoria Lisa; en Bernardo Larroudé a Juan Lionetto, Lorenzo Sereno y familia (Pedro Lorenzo, Vela Adela, Lorenzo América, Teresa M. de Lorenzo, Juan José, Alicia, Dora, Atilio Plácido Lorenzo -padre-, Miguel, Francisco y Lucía Teresa Sereno), Juan Álvarez, Lorenzo Chetto (colono), Felipe Ángel Gorini (padre), Delfini T. de Gorini y familia (Fidel Felipe, Francisco Fidel, Fidel Ángel, Felisa Carolina y José Carlos).

${ }^{4}$ Ver apéndice cartográfico para conocer la localización de las logias a la que nos referimos.
} 
Estas logias se desarrollaron como parte de un movimiento mayor que involucró a las diferentes provincias y territorios argentinos ${ }^{5}$. Lo interesante es rescatar, como plantea Bonaudo $^{6}$, que la sociabilidad masónica creada a partir de estas prácticas asociativas, en el plano de las ideas, fueron espacios privilegiados de elaboración, debate y discusión de los valores liberales, republicanos y democráticos; y en el terreno de las formas organizativas, por cuanto su estructura programática y sus pautas de integración y regulación, aparentemente incidieron en las nuevas formas del asociacionismo voluntario, operando como instrumentos de nuevas identidades.

En este artículo estudiamos las logias que surgieron en las primeras décadas del siglo XX. Centramos el análisis en la indagación de su origen y declinación, aspectos generales de su funcionamiento y las redes de vinculación con otras asociaciones de la sociedad. Asimismo, interpretamos la relación que establecieron con la Iglesia católica en tanto fueron asociaciones que disputaron con el catolicismo el rumbo que debía adquirir el territorio pampeano. Para abordar esta temática, analizamos fundamentalmente correspondencia entre las logias locales y la Gran Logia, y material confesional católico.

Conceptualmente este trabajo se enmarca en lo que hemos denominado la disidencia antirreligiosa. En este sentido, adherimos conceptualmente al planteo de Di Stefano ${ }^{7}$ acerca de que llamar religiosa a la disidencia anticatólica tiene dos sentidos:

el más obvio: lo es porque critica la religión, o cuanto menos, sus instituciones. Pero además cabe denominarla religiosa porque lo son la lógica que la guía y el capital simbólico en juego, que es el de los bienes de salvación, aunque se trate de atentar contra ese capital y -más que nada- contra quienes lo detentan. Etimológicamente, religión remite a la idea de relación, de lazo, de vínculo. Atacar símbolos, instituciones o ideas religiosas implica tomar parte en esa realidad relacional. La carga simbólica de lo sagrado, de lo trascendente, tiene su peso incluso en las actitudes más radicalmente "antirreligiosas".

\footnotetext{
${ }^{5}$ Entre ellos podemos citar: Bandieri, "Sociedad civil y redes de poder social", 53-68.; Susana Bandieri y Marisa Moroni, "Prácticas asociativas seculares, poder y política. Masones en Neuquén y espiritistas en La Pampa en la primera mitad del siglo XX", en Estudios de historia religiosa argentina (siglo XIX y XX), ed. Ana María T. Rodríguez (Rosario: Prohistoria-EdUNLPam, 2013), 77-97; Marta Bonaudo, "Liberales, masones, ¿subversivos?", Revista de Indias LXVII, no. 240 (s/f): 403-432; María Liliana Da Orden, "Inmigración y masonería: una perspectiva local (Mar del Plata, 1891-1930)" (ponencia presentada en IIo Seminario euro-argentino de historia de las redes masónicas atlánticas, Buenos Aires, 2014); Leandro Di Gresia, "Jueces de paz, masones y conservadores en la campaña bonaerense: Una aproximación a las redes vinculares en el sur de la provincia de Buenos Aires (Tres Arroyos, 1865-1910)", Mundo Agrario XI, no. 21 (2010); Marisa Moroni y Rodríguez, "Los anticlericales pampeanos: masones y espiritistas", en Historia de La Pampa I. Sociedad Política y Economía. 2da edición, revisada y ampliada, ed. Andrea Lluch y Claudia Salomón Tarquini (La Pampa: EdUNLPam, 2014), 499-509.

${ }^{6}$ Bonaudo, Liberales, masones, ¿subversivos?, 404.

${ }^{7}$ Roberto Di Stefano, "Disidencia Religiosa y Secularización en el siglo XIX Iberoamericano: cuestiones conceptuales y metodológicas", Projeto História 37 (2008): 158-59.
} 
Bien cabe entonces, la advertencia de Di Stefano:

entre disidencia religiosa y secularización existe una relación compleja, cuya naturaleza no podemos dar por descontado, porque la disidencia no es un mero producto de la secularización, que tampoco puede explicarse sin su concurso. Con la complicación adicional de que la secularización cualitativa -la pérdida del lugar cimental que ocupaba la religión en la vida colectiva de las sociedades de antiguo régimen- no comporta necesariamente un grado equivalente de secularización cuantitativa -la disminución del número de personas religiosas en la sociedad.

\section{Las logias locales: su carácter efímero}

El 16 de mayo de 1907, el Poder Ejecutivo de la Orden autorizó a José Sardella, Cándido Zúñiga, Martín de la Mata y Juan Dhers a constituir un Triángulo cuyo título distintivo fue Estrella de la Pampa del Valle de Santa Rosa ${ }^{8}$. En el mismo año, Alejandro Copello Podestá (Venerable Maestro), Juan Flamang (Primer Vigilante), Zacarías Higioni (Segundo Vigilante), Arturo E. Forteza (Orador) y Francisco González Rivero (Secretario) solicitaron, ante la Gran Logia Nacional regularizar la logia Libertad del Valle de General Acha $^{9}$. Al año siguiente, el poder Ejecutivo del Gobierno Simbólico de la logia autorizó a José Grassi, José Torti, Castor Lacerna, Humberto J. Matassi, Mariano Viartola, Eduardo Marchena, Francisco Badia y Joaquín de la Huerta a constituir la logia Luz de La Pampa en el Valle de General Pico ${ }^{10}$.

Estas logias surgieron en los principales núcleos urbanos del Territorio: General Acha fue uno de los dos primeros poblados del Territorio y su primera capital (1900-1902); Santa Rosa fue la capital a partir de 1902 y General Pico fue el principal núcleo poblacional del norte de La Pampa vinculado al desarrollo agrícola y la llegada del ferrocaril. Podemos afirmar que dichas logias nacieron en lo que se denomina la etapa de florecimiento de la masonería pampeana, en coincidencia con un proceso mayor de surgimiento de logias en la Patagonia, que operaron como constructoras de la institucionalidad moderna. Acordamos, como lo plantea Bandieri ${ }^{11}$ que

las incipientes poblaciones patagónicas, sobre todo las que fueron asiento de las nuevas autoridades territorianas, parecieron ofrecer alternativas válidas para consolidar cierto tipo de redes sociales de carácter laico y liberal. Estas formas

\footnotetext{
${ }^{8}$ Firma el decreto Emilio Gouchón, Legajo 954, Buenos Aires: Archivo de la Gran Logia Argentina, en adelante AGLA, 1907.

${ }^{9}$ Legajo 945, Buenos Aires: AGLA, 1908.

${ }^{10}$ Legajo 965, Buenos Aires: AGLA, 1908.

${ }^{11}$ Bandieri, "La masonería en la Patagonia. Modernidad liberal y asociacionismo masón en Neuquén (18841907)", Estudios sociales 38 (2010): 12.
} 
asociativas tuvieron un fuerte arraigo en las sociedades nuevas, lo cual les permitió una apropiación considerablemente mayor del espacio público local y regional, tal y como se evidencia en el pensamiento y acción de numerosos funcionarios $\mathrm{e}$ intelectuales de la época.

En este contexto, llama la atención que en la década siguiente surgiera el Triángulo Luz de La Pampa. En 1923 un grupo ciudadanos de la localidad de Catriló, solicitó a través de una nota al ministro de gobierno de la masonería argentina del rito escoses antiguo y aceptado, Alejandro Maidana, que se les permitiera trabajar "bajo los Auspicios del G. Oriente Argentino"12. Estos "hermanos" se comprometieron a obedecer las leyes y decretos de ese Cuerpo así como los que emanen de la Gran Logia ${ }^{13}$. Firmaban la nota Ángel B. Cámpora (Grado $3^{\circ}$ ), Mario Menenguzzi (Grado $1^{\circ}$ ), Juan B. Bigioli (Grado $1^{\circ}$ ), Juan José Cámpora (Grado $3^{\circ}$ ), Elías Jacinto $\left(\text { Grado } 3^{\circ}\right)^{14}$. La particularidad de esta logia es que surgió una década después que el resto, en una pequeña localidad del interior, a diferencia de las anteriores que fueron parte del proceso de construcción institucional de los principales centros urbanos del Territorio. Un dato significativo es que en Catriló, del mismo modo que en varias localidades del territorio pampeano, el proceso de poblamiento y urbanización no incluyó la realización de un templo. De esta manera, la presencia eclesial se realizaba a través de las misiones volantes que llevó a cabo la Congregación Salesiana. La inexistencia de una estructura institucional católica y la visita esporádica de un misionero pueden considerarse una evidencia empírica de que el catolicismo no había logrado anclar en esta sociedad y daba cabida a otras expresiones, en otras palabras, existía un sustrato liberal que justificó el desarrollo de Triángulo Luz de La Pampa en coincidencia con el arribo a localidad de migrantes que tenían experiencia previa en la masonería ${ }^{15}$.

En todos los casos, las logias pampeanas fueron incorporadas a la obediencia del Supremo Consejo y Gran Oriente y adhirieron al Gran Oriente del Rito Escocés Antiguo y Aceptado. Recordemos que en Argentina a fines de la década de 1850, los integrantes de diferentes logias crearon la institución masónica el Supremo Consejo y Gran Oriente para la República Argentina. Por sus filas circularon las personalidades más caracterizadas de la

\footnotetext{
${ }^{12}$ La nota no tiene fecha, pero la respuesta en la que se autoriza trabajar en la regularización es del 1 de marzo de 1923. La nota podría ser enviada en los meses de enero o febrero del mismo año.

${ }^{13}$ Hermano: Titulo fraternal con que se distinguen a los miembros de la francmasonería.

${ }^{14}$ Legajo 1426, Buenos Aires: AGLA, 1923.

${ }^{15}$ Desde 1896 con la entrega del Arzobispo de Buenos Aires, Uladislao Castellano, de gran parte del territorio pampeano a la Congregación Salesiana, hasta 1934 estos religiosos tuvieron jurisdicción religiosa sobre el Territorio y conformaron la Misión de la Pampa. La Congregación Salesiana, a través de la "Misión de La Pampa", desarrolló múltiples estrategias para dar respuestas a una diversidad territoriana caracterizada por una heterogénea organización del espacio (centros urbanos, pequeños poblados, zonas rurales) y una estructura poblacional compuesta por indígenas, criollos y distintos grupos de inmigrantes (italianos, españoles, alemanes). Como correlato de esta diversidad, se configuró la "Iglesia católica" con una impronta local, integrada a la vida social, política y económica. Rodríguez, "Secularización y catolicismo en el Territorio Nacional de La Pampa (1896-934)" (Tesis de doctorado en historia, UNICEN, 2013).
} 
época: presidentes de la República, ministros, legisladores, camaristas, oficiales del ejército, catedráticos y escritores. Esta institución experimentó las consecuencias del clima de agitación y cambio que afectaron al país en su tránsito hacia la modernidad. El historiador Carlos Mayo, estudioso del tema, señala que

en 1873, por ejemplo la masonería argentina se vio sacudida por una profunda crisis interna que culminó con la formación de tres agrupaciones rivales. En 1898, hubo una nueva ruptura: un grupo de masones separados del Supremo Consejo Oriente fundó la Gran Logia Nacional Argentina que reclamó para sí la genuina representación del llamado Rito escocés Antiguo. En 1902, un grupo de logias dependientes del Supremo Consejo y Gran Oriente decidió separase y fundar un nuevo Rito: el Azul. Lo hizo en disidencia con el Rito Escocés Antiguo que representaba la Gran Logia Nacional, aunque también en disconformidad con la renovación de autoridades del año 1902. Este hecho inauguró un periodo donde la disidencia fue frecuente y el choque de ideas, agravado por el enfrentamiento personal, terminó por alentar movimientos secesionistas de singular gravedad ${ }^{16}$.

La actividad masónica de las logias Estrella de la Pampa, Libertad y Luz de La Pampa fue propiciada y desarrollada por migrantes externos, fundamentalmente españoles e italiano $^{17}$. Este aspecto, explica porqué en su mayoría eran librepensadores con experiencia previa en la masonería situación que pone en evidencia cómo aún las pequeñas localidades de los territorios nacionales formaban parte de redes de vinculación de la masonería con alcance nacional e internacional. A modo de ejemplo, podemos citar el caso de Elías Jacinto que formó parte del Triángulo Luz de La Pampa y anteriormente participó en la logia Luz de la Pampa de Santa Rosa de Toay, y había sido iniciado en 1888 en la logia de Beyrouth (capital del Líbano).

\footnotetext{
${ }^{16}$ Carlos Mayo, "La masonería en crisis (1902-1922)", en Conflictos y Procesos de la Historia Argentina Contemporánea, tomo 5 (Buenos Aires: Centro Editor de América Latina, 1988), 4. Sobre los orígenes de la masonería se recomienda la consulta de Dévrig Mollès, La invención de la masonería. Revolución cultural: religión, ciencia y exilios (La Plata: Editora de la Universidad Nacional de La Plata, 2015) y "Masonería, historia y memoria: la cuestión de los orígenes", História da Historiografia 20 (julio de 2016): 139-156.

${ }^{17}$ Este aspecto que se corresponde con el proceso migratorio local que de acuerdo al primer Censo de Población de los Territorios Nacionales de 1912, la Pampa fue uno de los "nuevos" espacios con mayor expansión demográfica, alcanzando los ochenta mil habitantes. Para el II Censo Nacional de 1914, ya había superado los cien mil (más del doble de Chaco, uno de los Territorios más poblados). Según este censo la inmensa mayoría de los migrantes eran transoceánicos (el $28 \%$ de toda la población pampeana). Los españoles (13.966) fueron el grupo más importante que en forma conjunta con los italianos (11.106) y rusos (6.027) (agruparon más del 90\% de los migrantes transoceánicos. El resto se distribuyó en una veintena de nacionalidades que incluyó franceses, turcos, austriacos alemanes, portugueses, rumanos, ingleses, suizos, dinamarqueses, norte-americanos, uruguayos, chilenos, brasileros, paraguayos y otras nacionalidades. Ezequiel Ander Egg, La Pampa esbozo preliminar para un estudio de su estructura socio-económica. Vol. 1: Demografia, (Santa Rosa-La Pampa: Talleres Gráficos de la Dirección de Imprenta y Boletín Oficial de la Provincia de la Pampa, 1957), 58.
} 
Las logias de La Pampa tuvieron un carácter efímero. Las solicitudes de incorporación de hombres a la logia Estrella de La Pampa se iniciaron en 1908, registrándose ese año y el siguiente el mayor número de altas. Durante los 5 años de existencia formal, la logia contó con un total de 43 miembros. La incorporación a la institución fue desigual, concentrándose en los dos primeros años. El retiro de tres integrantes en 1910 y la falta de pago de cinco en 1911, da cuenta de que en su tercer año de existencia la actividad menguó para culminar sus actividades en el año $1912^{18}$. El 29 de enero de ese año, Arturo Guevara remitió una nota al Consejero de Interior informándole que "a causa de hallarla la mayoría de los hh del ... fuera del Valle, a causa de los trabajos de la cosecha, esta logia, en el día de la fecha, ha resulto declarar, sus tareas en receso por el término de dos meses"19. A partir de ese momento no existen registros de que la logia haya reiniciado sus actividades formales. En el caso de la logia Libertad del Valle de General Acha, las solicitudes de incorporación de hombres de la localidad se iniciaron en 1907, registrándose ese año el mayor número de altas. Durante los 4 años de existencia formal la logia contó con un total de 29 miembros. La incorporación a la institución fue desigual. La radiación por falta de pago de nueve miembros da cuenta que en el año 1909, la actividad de la logia menguó ${ }^{20}$. Finalmente culminó sus actividades en $1914^{21}$. Por su parte, las solicitudes de incorporación de hombres a la logia Luz de La Pampa de General Pico se iniciaron en 1909, durante los 6 años de su existencia formal, la logia contó con un total de 63 miembros. La incorporación a la institución fue desigual, concentrándose en el periodo 1909-1911 la mayor incorporación de integrantes: 52 del total. En el año 1912, comenzó su declive: disminuyeron abruptamente las solicitudes y de manera paralela sus integrantes dejaron de pertenecer, ya sea por radiación o bien por retiros y pases. Finalmente, culminó sus actividades en $1914^{22}$.

\footnotetext{
${ }^{18}$ Rodríguez, "Los masones pampeanos de principios del siglo XX. Un estudio de su perfil socio ocupacional y sus redes de vinculación de la Logia La Estrella de la Pampa en el Valle de Santa Rosa de Toay" (ponencia presentada en IIo Seminario euro-argentino de historia de las redes masónicas atlánticas, Buenos Aires, 2014).

${ }^{19}$ Legajo 1000, Buenos Aires: AGLA, 1912.

${ }^{20}$ Rodríguez, "Los cultores del laicismo: la masonería", en Te contemplamos desde las sendas del recuerdo. General Acha, más de 130 años de historia, eds. Selva Olmos, Rocío Guadalupe Sanchez y Federico Martocci (La Pampa: EdUNLPam, en prensa).

${ }^{21}$ Un dato significativo es desde el año 1912, en el mes de diciembre comienza a indicarse “.....A su vez debemos de comunicarnos que este Resp. Log. en los meses de diciembre, enero y febrero no trabaja en las ...recepción de convocatoria especial a los efectos de suma urgencia, por ser la época en que todos los HH del Valle tiene grandes ocupaciones, y se reanudan los trabajos para marzo de 1913. No obstante dejamos de formar buena nota y acuse de recibo a vuestro aunque no la regularidad debida por lo ya expuesto". Nota dirigida al Consejo S. Legajo 1003, Buenos Aires: AGLA, 1912.

${ }^{22}$ Rodríguez, "Los masones pampeanos de principios del siglo XX: el perfil socio ocupacional y las redes de vinculación de la Logia Luz de La Pampa, General Pico (1909-1914)" (ponencia presentada en XXII Jornadas de Investigación de la Facultad de Ciencias Humanas, General Pico, 10 y 11 de septiembre de 2015).
} 
Por último, Triángulo Luz de La Pampa (1923-1924) así como fue vertiginosa su conformación, también lo fue su desaparición. A través de un decreto del 17 de noviembre de 1924, el Gran Maestre declaró al Triángulo Luz de Catriló (La Pampa) en sueño irregular e invitó a su presidente a entregar al Departamento del Interior, dentro del término de 20 días y en calidad de depósito la Carta Constitutiva, timbres, sellos, registros, libros, joyas, metales y otras pertenencias. Ángel Cámpora, quien había sido uno los que propició su conformación, fue trasladado a Córdoba como Relevante del Ferrocarril a principios del año 1924. Si bien había dejado a cargo a Juan J. Cámpora y las planchas firmadas para elevar a la Gran Logia nunca se enviaron, la falta de presentación de la documentación fue una de las razones que justificó el decreto que estableció el paso al estado de "sueño",23.

El carácter efímero de estas logias se explica, a nuestro entender, por procesos de la época que afectaron su existencia. Sin duda, la movilidad laboral de quienes en muchos casos fueron los que propiciaron su surgimiento fue una de las causas centrales. Nos referimos a jueces de paz, jefes de correo, jefes de estación, comisarios y "empleados del Estado" que en varias oportunidades fueron trasladados a otras provincias o territorios. Frente a esta situación las logias tendieron a menguar su accionar hasta desaparecer. Otro proceso que debe atenderse es el de las consecuencias de la Ley Saenz Peña en el Territorio, que llevó a la creación del Partido Socialista, en el año 1913, y del Partido Radical, en el año 1916. Ambos cobijaron a integrantes de las logias que encontraron en estos "nuevos espacios institucionales" otras posibilidades de dirimir los destinos de estos "nuevos espacios".

\section{Las logias locales: su carácter efímero}

Los integrantes de la logia concibieron que, a través de esta forma asociativa, tenían la posibilidad de insertarse en el ámbito público local y desarrollar, bajo los principios que los guiaban, la construcción ${ }^{24}$ de una sociedad que estaba en pleno proceso de conformación de su estructura institucional, política, social y cultural. Tal como sostiene Bandieri en relación a los "nuevos espacios", facilitaron la inserción de aquellos inmigrantes que concibieron la posibilidad de construir "nuevas sociedades" en base a los ideales de libertad, igualdad y fraternidad y bregaron para que los ciudadanos se realizaran a través de la "Ciencia, la Justicia y el Trabajo".

En este sentido, los integrantes de la logia se insertaron en diferentes ámbitos locales en lo que se definía el destino de estos "nuevos espacios" que habían sido

\footnotetext{
${ }^{23}$ Rodríguez, "El carácter efímero de la masonería en los territorios del sur. El caso de la Triángulo Luz de La Pampa de Catriló" (ponencia presentada en VII Jornadas de Historia de la Patagonia, Santa Rosa, La Pampa, del 2 al 4 de noviembre de 2016).

${ }^{24}$ Bandieri, Sociedad civil y redes de poder social, 53.
} 
"conquistados al indio". El Concejo Municipal como lugar político institucional fue uno de los elegidos, era el espacio donde los territorianos ejercían su ciudadanía política. Recordamos que en los territorios nacionales los habitantes no tenían derecho a elegir a los gobernadores y, en consecuencia, el Concejo era el ámbito donde se llevaba a cabo la lucha política y desde donde se proyectaba el desarrollo local ${ }^{25}$. Otro cargo local donde se desempeñaron fue como Juez de Paz. También se insertaron en las estructuras de las asociaciones de inmigrantes, específicamente en las comisiones directivas de las sociedades italianas y en las sociedades de españoles. Además, participaron de la construcción de lugares culturales como las bibliotecas locales.

La disímil participación de los integrantes de las logias en diferentes ámbitos muestra cómo su accionar se forjó más allá de la propia institución y sus adherentes se integraron a otras instituciones del medio, que formaban parte de la vida política y la sociabilidad local. Así los masones pampeanos fueron artífices de la trama de relaciones sociales locales y, como lo han planteado algunos investigadores, pretendieron influir y dirigir la sociedad a partir de sus ideales ${ }^{26}$. En el caso de las logias pampeanas, fueron una pieza clave en el proceso de construcción de la institucionalidad política local basada en los principios de la democracia liberal. Los integrantes de la logia Luz de La Pampa de General Pico, por ejemplo, trabajaron para que la localidad adquiera el status de municipio. En una nota al consejero del Interior de la Gran Logia expresaban al respecto que:

...adheridos completamente a la idea de solidaridad, la pondremos en práctica en la oportunidad que tengamos en esta, mas estando próximo según pedido del Gobernador del Territorio al Sr. Ministro del Interior de la creación de Municipalidades en algunos pueblos del Territorios que por su número de habitantes estén en condiciones de tenerlas y este Valle hace tiempo cuenta con un número más que excesivo del que la Ley exige ${ }^{27}$.

Recordemos que, según la Ley $\mathrm{N}^{\circ} 1532$ de organización de los Territorios Nacionales de 1884, para alcanzar la categoría de municipalidad la localidad debía reunir una cantidad mínima de 1.000 vecinos y luego el Poder Ejecutivo autorizaba la creación de

\footnotetext{
${ }^{25}$ La Ley Orgánica 1532 habilitaba a los habitantes de los territorios a participar de las elecciones de concejos municipales y de jueces de paz cuando las comunas superaban los 1.000 habitantes. Se trataba de un ejercicio limitado de los derechos cívicos, porque no contemplaba la posibilidad de elegir candidato para la gobernación o para el ámbito nacional. Los concejos municipales estaban compuestos por cinco miembros, mayores de edad y domiciliados en el distrito, que a su vez elegían entre ellos un presidente, encargado de ordenar los debates y representar a la localidad en sus relaciones oficiales. Con tres ediles se tenía quórum para sesionar. Los miembros del concejo duraban dos años en sus funciones, el cargo era gratuito y se renovaba por mitad cada año, debiendo sortearse al efecto los que se retirarían la primera vez. Moroni, Folco, Lanzillota, Zink y Bergia, Evolución política entre 1890-1950, 321-368.

${ }^{26}$ Nos referimos fundamentalmente a los trabajos citados con anterioridad de Bandieri y Bonaudo.

${ }^{27}$ Nota al Consejero del interior, 16 de agosto de 1911. Legajo 1013, Buenos Aires: AGLA, 1913.
} 
un Concejo electivo, esa situación les permitía a los pobladores elegir autoridades y tomar decisiones respecto al funcionamiento de la comuna, aunque el gobierno nacional se reservó el derecho de intervenirlos si consideraba que había irregularidades, si los concejales no actuaban correctamente o lo hacían con demasiada independencia. General Pico, alcanzó esta categoría en 1912.

También los integrantes de las logias fueron una pieza clave en el movimiento provincialista. En 1907 propiciaron la creación del Comité Territorial Pro-Autonomía. Precisamente, por iniciativa de Santiago Ortiz y de Arturo Castro, este último integrante de la logia, se formó una comisión provisoria con vistas a institucionalizar y sistematizar las acciones. De este modo, convocaron a una asamblea y el 20 de noviembre de 1907 sus participantes crearon el Comité Territorial Pro-Autonomía, presidido por el juez letrado Miguel Duarte $^{28}$. Además de Castro, también participó del movimiento Arturo Guevara que fue Vocal del Comité Territorial Pro-Autonomía ${ }^{29}$. En 1908, Juan Lorusso, Eudoro Turdera y Luis Camussi, este último fue un activo miembro de la logia, fundaron el periódico La Autonomía que fue el órgano de difusión del Comité hasta que decidieron cerrarlo como forma de protesta por la dilación del pedido autonomista ${ }^{30}$.

El reclamo provincialista en el Territorio se remonta a los inicios del siglo XX y con distinta intensidad estuvo presente durante los primeros cincuenta años. La Ley 1532, establecía como mínimo 60.000 personas para cambiar el status jurídico y con ello gozar de los beneficios que esto implicaba: elegir los gobernantes, tener la posibilidad de ser candidatos, poseer independencia económica ${ }^{31}$. En 1909, cuando el Parlamento trató el presupuesto del Territorio Nacional, el diputado Pedro Olegario Luro ${ }^{32}$ les solicitó a sus pares enfáticamente que incrementaran la partida destinada a La Pampa y aprovechó el momento para informar sobre las pretensiones autonómicas de sus habitantes, un deseo que él compartía por interés personal porque poseía tierras que había heredado de su suegro Ataliva Roca. En su visita a Santa Rosa, el Comité le ofreció un banquete que contó con

\footnotetext{
${ }^{28}$ Miguel Duarte fue el creador de la logia Luz de La Pampa. Una logia que funcionó en Santa Rosa, en 1906.

${ }^{29}$ Zink, "Tenemos la pretensión de ser provincia. Actores y prácticas autonomistas en el Territorio Nacional de La Pampa (1890-1930)", en En la vastedad del "desierto". Estado, prácticas y actores sociales (18841958), eds. Enrique Mases y Zink (Rosario: Miño y Dávila-EdUNLPam, 2015).

${ }^{30}$ En 1913 se reabrió y quedó a cargo de Arturo Castro y Marcos Molas, si bien continuó con la misma orientación, lo hizo de manera independiente de la organización y se manifestó al margen de identificaciones político-partidarias. Zink, Tenemos la pretensión de ser provincia, 36.

${ }^{31}$ Pedro Olegario Luro Nació el 6 de marzo de 1860 en Buenos Aires, en una familia vasca. En 1884 se graduó de médico. Fue legislador en Buenos Aires durante diez años y diputado nacional de 1898 a 1912, por el Partido Autonomista Nacional. Su vinculación con el suelo pampeano se debió a su casamiento con Arminda Roca, hija de Ataliva, propietario de tierras en el territorio. Encabezó una gira por el Territorio para la firma de un petitorio de apoyo para que Pampa Central accediera a la categoría de provincia, que entregó al Congreso el 28 de mayo de 1915. Fue miembro del Jockey Club porteño. Participó en la persecución de anarquistas y extranjeros en 1910, y redactó textos de corte xenófobo. Biografías Pampeanas, Arte Política Historia Deportes Ciencia Periodismo en: http://biografiaspampeanas.blogspot.com.ar/

${ }^{32}$ Moroni, Folco, Lanzillota, Zink y Bergia, Evolución política entre 1890-1950, 140.
} 
una importante concurrencia de vecinos para demostrarle el apoyo a su iniciativa. Luro inició una campaña pro autonomía en el Territorio junto con integrantes del Comité y en varias localidades se crearon agrupaciones, luego viajaron a Capital Federal para entrevistarse con Figueroa Alcorta ${ }^{33}$ y entregarle una nota. El presidente respondió que se ocuparía del asunto a través del Ministerio del Interior; los autonomistas tenían la expectativa de concretar la provincia en el marco de los festejos del centenario de la Revolución de Mayo ${ }^{34}$, situación que como sabemos recién se efectivizó en el año 1952.

En este contexto, más allá de estas participaciones individuales, la logia Estrella de la Pampa tomó posición explícita. En una nota al consejero de Gobierno, del 20 de junio firmada por Arturo Guevara (Venerable), José Safigueroa, José Sardella y Luis M. Camussi expresaba:

La Au. y Res. Log "Estrella de la Pampa [...] ha resuelto, en tenida fecha 18 de este mes, dirigirse a vos rogándoos queráis hacernos su intérprete ante el gobierno de la Orden, a fin de que penetrándose de la Justicia y bondad del anhelo del pueblo pampeano, lo haga suyo y contribuya con su poderosa influencia a conseguir la autonomía que con tanto amor recaba en estos instantes de los altos poderes nacionales.

Entrar a reseñar las razones en que se funda este anhelo seria repetir lo que está en el conocimiento de todos y la historia nos enseñan desde los tiempos más remotos: es la ambición legítima y noble que anima a los espíritus elevados que teniendo el convencimiento de sus méritos, tratan de obtener la independencia que los coloca a nivel de sus iguales para ocupar su energías en aras del progreso y contribuir al común engrandecimiento amparados por la libertad.

Son pues, justos los ideales que el pueblo de la Pampa persigue, y lejos de poderse calificar de utópicos, están basados en los firmes cimientos de las cifras, para apoyar sus proyectos económicos y en la ley para reclamar sus derechos.

La prensa de todo el país ha ocupado sus columnas con la enumeración de las riquezas del Territorio y sus datos estadísticos generales, llegando casi todos a la conclusión de que, autónoma, la Pampa ocuparía un lugar entre las provincias más adelantadas de la República. Su población supera en mucho a la que la ley exige a los territorios nacionales para erigirlos su provincia: sus rentas sobrarían para atender los servicios públicos y costearse una administración hasta de lujo (?) y sería una manifiesta injusticia mencionar si quiera que no tiene hombres aptos para dirigir sus destinos. La honradez caracteriza a los valientes pobladores de estas regiones, ayer no más dominios del salvaje y hoy floreciente fuente de progreso, gracias a la constancia y labor de los que la elevaron a tal altura y el patriotismo más

\footnotetext{
${ }^{33}$ La comitiva se entrevistó con el Presidente al margen de la participación del gobernador y éste acusó a Luro de posicionarse para obtener una senaduría. El presidente José Figueroa Alcorta también pertenecía a la masonería y adhería al Rito escocés. Mollès, “¿Derecha o izquierda? El anticlericarismo argentino frente a la cuestión social (1904-1910)", Travesía 14-15 (2012-2013): 258.

${ }^{34}$ Zink, Tenemos la pretensión de ser provincia, 39.
} 
puro anima sus pechos. Así en todos los pueblos, la honradez y el patriotismo animan a los hombres de gobierno, todos los pueblos serían grandes.

Penetrada de todo esto es que esta Aug. y Res. Logia, reconociendo el derecho que asiste al pueblo de la Pampa, lo justo de su demanda y la nobleza de ambición, ha resulto pedir al Gobernador (interino) que se digne a considerar la gran nobleza del paso que ese pueblo quiere dar y coopere con todo su poder para que pueda realizarlo, con el convencimiento de que este acto encuadra dentro de los nombres ideales masónicos y sería una victoria más anotar en la historia de su acción benefactora y progresista.

Considero innecesario enumerar las ventajas que este cambio de gobierno traería al Territorio y al país, pues no escaparán al sabio criterio de los poderosos Hn. que rigen el gobierno de nuestra Orden.

Convencido pues, de que será tomada en consideración y favorablemente apoyada nuestra demanda, que es la de este vecindario, os envía la expresión de sus respetos y el abrazo fraternal ${ }^{35}$.

La respuesta no se hizo esperar. Y el Gobernador de la Orden se comprometió a coadyuvar a la obtención de la autonomía política del Territorio. Si bien no tenemos material documental para interpretar cómo cristalizó ese apoyo a la solicitud de los autonomistas masones, es una evidencia que la militancia de los pampeanos encontró eco en sectores de la masonería a nivel nacional.

\section{Enemigos de la Iglesia: algunos ejemplos}

En La Pampa la presencia confesional católica fue hegemonizada por la Congregación Salesiana a quien el Arzobispo de Buenos Aires, Uladislao Castellano, otorgó la casi totalidad del Territorio. A través de la Misión de La Pampa (1896-1934), los salesianos se propusieron construir una sociedad pampeana católica. Para ello, desarrollaron múltiples estrategias con la finalidad de dar respuestas a una diversidad territoriana caracterizada por una heterogénea organización del espacio (centros urbanos con pequeños poblados y una amplia zona rural, con diferencias regionales) y una estructura poblacional compuesta por indígenas, criollos y distintos grupos de inmigrantes (italianos, españoles, alemanes, entre otros). Así, la Misión de La Pampa se desplegó a partir de la conjunción de una serie de estrategias combinadas: el desarrollo de una estructura eclesial focalizada en la zona más poblada del Territorio, la implementación de un sistema de misiones ambulantes con destino a zonas rurales y al Far West pampeano, la ampliación del personal de cada centro de misión, el impulso de la educación religiosa y el asociacionismo de los laicos.

\footnotetext{
${ }^{35}$ Legajo 962, Buenos Aires: AGLA, 1909.
} 
El objetivo de construir una sociedad pampeana católica colisionó con los objetivos de quienes integraron las logias locales que pretendían organizar el Territorio bajo los principios masónicos de la modernidad liberal. En el contexto de lo que podríamos denominar "el pacto laico" "36 argentino, los masones bregaron por la separación entre la Iglesia y el Estado y frenar la creciente hegemonía del catolicismo. De este modo, las críticas al catolicismo, y en mayor medida a sus instituciones, fueron una constante. Las formas que adquirió la contestación fue diversa y osciló entre la blasfemia, la denuncia y en algunos casos hasta la oposición concreta a medidas tomadas por las Iglesia.

El periódico católico Brujulilla de La Pampa consignó un hecho perpetrado por la masonería en General Acha:

A las dos de la tarde del veinte de diciembre de 1908 el "partido popular", que la Iglesia consideró como el "partido masónico", formado por un centenar de "indios" encabezados por el juez de paz, Nicolás Ratto, Arturo Fortezza, escribano público, armaron una "algarada bombástica" al desfilar ante la iglesia al grito de "¡Abajo los cuervos!” y “¡Abajo los curas!”,37.

Los masones de General Pico cuestionaron ante las autoridades de la logia a nivel nacional que un "profano y masón" recientemente llegado a la localidad procedente del Valle de Chivilcoy mantenía vínculos con la Iglesia local. Según manifestaban, "lamentablemente para nosotros en razón que el referido h. sus vínculos de amistad desde el primer momento han sido con nuestros enemigos los clericales.” Agregaban que

con fecha 25 de mayo dio su primera función musical en el local que se alquila para templo eclesiástico, en igual forma el 9 de julio por último al contraer en segundas nupcias lo ha hecho por medio de la Iglesia cosa que nos han llamado altamente la atención por cuanto nos han sorprendido como masón.

Por su parte los masones de Catriló denunciaron ante las autoridades de la Gran Logia que estaba "en peligro" dado que "tenemos antecedentes concretos que en este Valle se está trabajando para hacer una Iglesia que está bajo el mandato del famoso cuervo Farinati. ${ }^{, 38}$ Ante esta situación, solicitaron que de manera urgente autorizaran el pedido de

\footnotetext{
36"La noción de "pacto laico" no describe una realidad empírica. Reúne y problematiza un conjunto de hechos ligados a la separación de las iglesias y del Estado (...) El pacto no implica un consenso, ni siquiera un acuerdo explícito. Requiere en cambio, reconocer en el otro lo "no negociable" y rebasar el horizonte de un conflicto frontal para proyectarse en un futuro diferente del presente (...)". Jean Baubérot, "Los umbrales de la laicización en la Europa Latina y la recomposición de lo religioso en la modernidad tardía", en La modernidad religiosa: Europa Latina y América Latina en perspectiva comparada, ed. Jean Pierre Bastian (México DF: Fondo de Cultura Económico, 2005), 100.

${ }^{37}$ La Brujulilla de La Pampa V, no. 241, 20 de marzo de 1909.

${ }^{38}$ Nota del 26 de marzo de 1923 de Ángel Cámpora y Juan B. Bigioli al Ministro de Gobierno de la masonería
} 
cuatro nuevas iniciaciones. La razón que fundamentaba la petición era para "cumplir con su deber" de bregar por los ideales de libertad, igualdad y fraternidad. En este contexto, la posibilidad de la presencia de un sacerdote con pretensiones de construir un templo en la localidad atentaba contra los principios y las ideas masónicas. Un dato significativo es que en Catriló, del mismo modo de varias localidades del territorio pampeano, el proceso de poblamiento y urbanización no incluyó la realización de un templo. De este modo, la presencia eclesial se realizaba a través de las misiones volantes que llevó a cabo la Congregación Salesiana. De manera permanente, desde cada centro de misión partían los misioneros hacia sus giras apostólicas a distintos centros urbanos que no poseían sacerdote fijo, a las zonas rurales y a las colonias. Los recorridos se organizaban de modo tal que la totalidad del Territorio recibiera atención. En el caso de Catriló el sacerdote llegaba a partir de una misión que partía de la parroquia de Santa Rosa, se hacía en sulky e incluía a numerosos pueblos y colonias, entre los cuales figuran Uriburu, Miguel Cané, Anguil, Catriló, La Araña, Inés y Carlota, Ataliva Roca, Mirasol, Macachín, Lonquimay, La Gloria, Espiga de Oro y Quemú Quemú ${ }^{39}$. La referencia a la que se refieren los masones es la misión del año 1923, cuando Farinati visitó las siguientes localidades: Anguil en febrero y septiembre; San José en octubre; Lonquimay en marzo y septiembre; Ataliva Roca en abril y noviembre; Rolón en octubre; Catriló en febrero, julio y septiembre; La Gloria en mayo; Relmo en mayo; Naicó en mayo y noviembre; y Quemú Quemú, en marzo y octubre.

La figura de Farinati, cura párroco de la Iglesia de Santa Rosa y Vicario Foráneo de La Pampa ${ }^{40}$, fue central en el enfrentamiento con los grupos anticlericales, fundamentalmente con los socialistas de Santa Rosa.

\footnotetext{
Argentina del Rito Escoses Antiguo y Aceptado, Alejandro Maidana. Juan Farinati fue el segundo vicariato de la Misión de La Pampa (1915-1930). Su vicariato coincidió con la organización definitiva de la Misión de La Pampa. La Sacra Congregación Consistorial además de transferir la sede a Santa Rosa dio cabida a una nueva organización institucional, fundamentalmente a través de tres instituciones que las combino para asegurar los fines de la misión: el nombramiento de los misioneros ambulantes como parte del personal de los centros, la creación de capellanías y la construcción de colegios. En este contexto, la Parroquia de Santa Rosa se transformó en un centro de misión y en un centro educativo. También, Farinati editó El Cruzado, considerado como "la buena prensa", en oposición a los periódicos socialistas que circularon por el Territorio, fundamentalmente Germinal. Para hacer frente a esta "arremetida" se sustentó en la feligresía. En este sentido, reorganizó las iniciales estructuras de los laicos de Santa Rosa, el Apostolado de la Oración y la Asociación de María Auxiliadora, y fundó con un grupo de hombres la Compañía del Santísimo Sacramento, que se sumó a su militancia contra los grupos anticlericales. Como parte de esta expresión de fortalecimiento promovió la institucionalización de la peregrinación anual al santuario de María Auxiliadora de Toay e inició una serie de peregrinaciones al santuario de Nuestra Señora de Lujan. Una mención especial merece el Círculo de Obreros Católicos creado en La Pampa, en 1911 por iniciativa del cura Vaira. Este grupo, si bien no logró incidir ni cuantitativa ni cualitativamente en el movimiento obrero local, fue en una fuerza de militancia con un protagonismo indiscutido. Rodríguez, Secularización y catolicismo en el Territorio Nacional de La Pampa.

${ }^{39}$ Cincuenta años de la Obra Salesiana en La Pampa Central, 1896 a 1946 (Buenos Aires: Mimeo, Archivo Central Salesiano, s/f).

${ }^{40}$ Juan Farinati (1869-1960) nació en Merano (Italia). Su familia emigró a la Argentina en 1888. Fue alumno
} 
La respuesta de Gran Logia no se hizo esperar,

Comuníquese al Triángulo (....) que estando en instancia de regularización no es posible por ahora acceder a lo solicitado mientras no se cumplan los trámites que marcan los reglamentos de la orden. (.....) de incorporarlos ese Triángulo definitivamente (...) Mientras tanto este gobierno vería con agrado por los medios que ese Triángulo considere conducente se inicie y afilie la campaña liberal en ese valle con motivo del hecho que menciona ${ }^{41}$.

Los objetivos de la autoridades de la Gran Logia de fomentar el fortalecimiento del Triángulo Luz de la Pampa no prosperó, no obstante ello la Iglesia en Catriló recién se inauguró en el 1938 por el sacerdote Esteban Punto. Evidentemente en la sociedad local existió, como señalamos con anterioridad, un sustrato liberal o librepensador por el que no estaban dadas las condiciones para que la Iglesia Católica hiciera pie en la localidad con uno de sus principales símbolos como es un templo.

También el clero identificó la presencia y el accionar de grupos masónicos institucionalizados. En la visita extraordinaria de 1908, Pedro Ricaldone, delegado del rector mayor Don Rua, manifestó en su informe que "la población de Santa Rosa es de

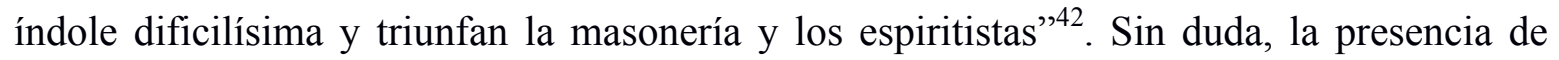
Estrella de La Pampa, con accionar en la capital del Territorio pusieron en peligro las pretensiones de la Misión de La Pampa.

\section{Conclusiones}

En un contexto de creciente secularización, la masonería surgió como una de las múltiples prácticas asociativas que intermedió entre la sociedad civil y el poder político. La masonería pampeana fue artífice en los procesos de construcción política, sobre todo en la adquisición del status de municipalidad en las localidades que no revestían este carácter y

del Colegio Pío IX, formuló su profesión en 1890. Comenzó sus primeras actividades en la vida salesiana como asistente y maestro en el colegio Pio IX. Trabajó luego en las casas de San Nicolás de los Arroyos y La Plata. Recibió el sacerdocio de manos de Mons. Juan Cagliero el 16 de septiembre de 1895 en la iglesia San Juan Evangelista de La Boca. Sus primicias sacerdotales las reservó para la casa de Santa Catalina como encargado del Oratorio Festivo. En 1900 fundó la obra salesiana en Ensenada, luego fue a Rosario y por último su destino fue la Pampa. Falleció en la casa de Institución Juan Segundo Fernande de Boulogne, el 21 de enero de 1960, a los 90 años y 65 de sacerdocio. Biografía anónima Juan Farinati, Archivo Salesiano de Buenos Aires, Argentina.

${ }^{41}$ Nota al Consejero del Interior Santiago Maidana, 3 de abril de 1923. Legajo 1426, Buenos Aires: AGLA, 1923.

42،...Pedro Ricaldone, quien llegó a ser Rector Mayor de la congregación Salesiana de Don Bosco entre 1932 y 1951, fue enviado en 1898 a visitar las casas salesianas de América del Sur, y en 1908 llegó a la Pampa.” P. Ricaldone. Informe de la visita extraordinaria de 1908, Buenos Aires, Archivo Central Salesiano. 
en la lucha por la provincialización del Territorio. Asimismo, sus integrantes se insertaron en lugares estratégicos, como los concejos deliberantes, el juzgado de paz, las bibliotecas, las asociaciones de migrantes, donde trabajaron para lograr que el "nuevo espacio" territoriano se organizara en torno a los principios de la democracia liberal y la laicidad. Por esta razón, estos actores de la esfera pública moderna tuvieron un claro perfil anticlerical, fundamentalmente se opusieron al clero y su finalidad de construir una sociedad católica pampeana.

La particularidad de estas asociaciones fue el carácter efímero de su existencia: Libertad duró cuatro años, Estrella de La Pampa y Luz de La Pampa duraron seis años, y Triángulo Luz de La Pampa duró un año. Esta temporalidad limitada se explica en parte por la movilidad de algunos de sus integrantes y también por el surgimiento de los partidos socialista y radical que abrieron la posibilidad de nuevas formas asociativas desde donde proyectar el desarrollo político, económico, cultural y social del Territorio.

Nos queda el desafío de indagar la inserción de los integrantes de las logias en estos partidos políticos e indagar la perspectiva de estos librepensadores en las nuevas estructuras.

\section{Fuentes primarias}

Biografias Pampeanas, Arte Politica Historia Deportes Ciencia Periodismo en http://biografiaspampeanas.blogspot.com.ar/

Biografía anónima Juan Farinati, Archivo Central Salesiano de Buenos Aires, Argentina (ACS).

Cincuenta años de la Obra Salesiana en La Pampa Central, 1896 a 1946. Buenos Aires: Mimeo. ACS.

La Brujulilla de La Pampa V, no. 241, 20 de marzo de 1909.

Legajo 945. Buenos Aires: Archivo de la Gran Logia Argentina (AGLA), 1908.

Legajo 954. Buenos Aires: AGLA, 1907.

Legajo 962. Buenos Aires: AGLA, 1909.

Legajo 965. Buenos Aires: AGLA, 1908.

Legajo 1000. Buenos Aires: AGLA, 1912.

Legajo 1003. Buenos Aires: AGLA, 1012.

Legajo 1013. Buenos Aires: AGLA, 1913.

Legajo 1426. Buenos Aires: AGLA, 1923. 


\section{Bibliografía}

Ander Egg, Ezequiel. La Pampa esbozo preliminar para un estudio de su estructura socioeconómica. Vol. 1: Demografía. Santa Rosa-La Pampa, Talleres Gráficos de la Dirección de Imprenta y Boletín Oficial de la Provincia de la Pampa, 1957.

Bandieri, Susana. "La masonería en la Patagonia. Modernidad liberal y asociacionismo masón en Neuquén (1884-1907)". Estudios sociales 38 (2010): 9-38.

Bandieri, Susana. "Sociedad civil y redes de poder social en los territorios nacionales del sur: Neuquén, Patagonia argentina. 1880-1907”. Boletín Americanista LVII, no. 57 (2007): 53-68.

Bandieri, Susana y Marisa Moroni. "Prácticas asociativas seculares, poder y política. Masones en Neuquén y espiritistas en La Pampa en la primera mitad del siglo XX". En Estudios de historia religiosa argentina (siglo XIX y XX). Editado por Ana María T. Rodríguez. Rosario: Prohistoria-EdUNLPam, 2013.

Baubérot, Jean. "Los umbrales de la laicización en la Europa Latina y la recomposición de lo religioso en la modernidad tardía". En La modernidad religiosa: Europa Latina y América Latina en perspectiva comparada. Editado por Jean Pierre Bastian. México DF: Fondo de Cultura Económico, 2005.

Bonaudo, Marta. "Liberales, masones, ¿subversivos?". Revista de Indias LXVII, no. 240 (2007): 403-432.

Da Orden, María Liliana. "Inmigración y masonería: una perspectiva local (Mar del Plata, 1891-1930)". Ponencia presentada IIo Seminario euro-argentino de historia de las redes masónicas atlánticas, Buenos Aires, 2014.

Mollès, Dévrig. "¿Derecha o izquierda? El anticlericarismo argentino frente a la cuestión social (1904-1910)". Travesía 14-15 (2012-2013): 249-276.

Mollès, Dévrig. La invención de la masonería. Revolución cultural: religión, ciencia y exilios. La Plata: Editora de la Universidad Nacional de La Plata, 2015.

Mollès, Dévrig. "Masonería, historia y memoria: la cuestión de los orígenes". História da Historiografia 20 (2016): 139-156.

Di Gresia, Leandro. "Jueces de paz, masones y conservadores en la campaña bonaerense: Una aproximación a las redes vinculares en el sur de la provincia de Buenos Aires (Tres Arroyos, 1865-1910)". Mundo Agrario XI, no. 21 (2010): .

Di Stefano, Roberto. "Disidencia Religiosa y Secularización en el siglo XIX Iberoamericano: cuestiones conceptuales y metodológicas”. Projeto História 37 (2008): 158-159.

Mayo, Carlos. "La masonería en crisis (1902-1922)". En Conflictos y Procesos de la Historia Argentina Contemporánea, tomo 5. Buenos Aires: Centro Editor de América Latina, 1988. 
Moroni, Marisa, María Esther Folco, María de los Ángeles Lanzillota, Mirta Zink y Martín Bergia. "Evolución política entre 1890-1950". En Historia de La Pampa. Sociedad, política, economía. Desde los poblamientos iniciales hasta la provincialización (ca. 8000 AP a 1952). Editado por A. Lluch y C. Salomón Tarquini. Santa Rosa: EdUNLPam, 2008.

Moroni, Marisa y Ana María T. Rodríguez. "Los anticlericales pampeanos: masones y espiritistas". En Historia de La Pampa I. Sociedad Política y Economía. 2da edición, revisada y ampliada. Editado por Andrea Lluch y Claudia Salomón Tarquini. La Pampa: Miño y Dávila-EdUNLPam, 2014.

Rodríguez, Ana María T. "El carácter efímero de la masonería en los territorios del sur. El caso de la Triángulo Luz de La Pampa de Catriló". Ponencia presentada en VII Jornadas de Historia de la Patagonia. Santa Rosa, La Pampa, del 2 al 4 de noviembre de 2016.

Rodríguez, Ana María T. "Los cultores del laicismo: la masonería”. En Te contemplamos desde las sendas del recuerdo. General Acha, más de 130 años de historia. Editado por Selva Olmos, Rocío Guadalupe Sanchez y Federico Martocci. La Pampa: EdUNLPam, en prensa.

Rodríguez, Ana María T. "Los masones pampeanos de principios del siglo XX. Un estudio de su perfil socio ocupacional y sus redes de vinculación de la Lomasia La Estrella de la Pampa en el Valle de Santa Rosa de Toay”. Ponencia presentada en IIo Seminario euro-argentino de historia de las redes masónicas atlánticas. Buenos Aires, 2014

Rodríguez, Ana María T. "Los masones pampeanos de principios del siglo XX: el perfil socio ocupacional y las redes de vinculación de la Logia Luz de La Pampa, General Pico (1909-1914)". Ponencia presentada en XXII Jornadas de Investigación de la Facultad de Ciencias Humanas. General Pico, 10 y 11 de septiembre de 2015.

Rodríguez, Ana María T. "Secularización y catolicismo en el Territorio Nacional de La Pampa (1896-934)". Tesis de doctorado en historia, UNICEN, 2013.

Zink, Mirta. "Tenemos la pretensión de ser provincia. Actores y prácticas autonomistas en el Territorio Nacional de La Pampa (1890-1930)". En En la vastedad del "desierto". Estado, prácticas y actores sociales (1884-1958). Editado por Enrique Mases y Mirta Zink. Rosario: Miño y Dávila-EdUNLPam, 2015. 